\begin{tabular}{c|l|l|l}
$\begin{array}{c}\text { Case Reports in } \\
\text { Oncology }\end{array}$ & $\begin{array}{l}\text { Case Rep Oncol 2011;4:204-210 } \\
\text { DOI: 10.1159/000327698 }\end{array}$ & $\begin{array}{l}\text { Published online: } \\
\text { April 6, 2011 }\end{array}$ & $\begin{array}{l}\text { O 2011 S. Karger AG, Basel } \\
\text { ISSN 1662-6575 } \\
\text { www.karger.com/cro }\end{array}$ \\
\hline
\end{tabular}

\title{
Optimal Duration of Imatinib Mesylate Therapy in Metastatic Gastrointestinal Stromal Tumours
}

\author{
Ruth Gauden Stan Gauden \\ W.P. Holman Clinic, Launceston General Hospital, Launceston, Tas., Australia
}

\section{Key Words}

Gastrointestinal stromal tumour - Metastasis - Imatinib mesylate - Treatment duration . Treatment interruption

\begin{abstract}
While current literature provides evidence that imatinib mesylate has significant activity in patients with advanced and metastatic gastrointestinal stromal tumour (GIST), and highlights the potential for the development of anticancer drugs based on specific molecular abnormalities present in cancers, specific recommendations concerning the optimal duration of therapy remain controversial. This case presents the favourable outcome of a patient who originally presented almost 9 years ago with widespread, bulky, metastatic GIST involving the abdomen and pelvis. A sustained, complete response was achieved with imatinib and prompted an interruption in treatment 7 years after initial presentation. The disease reoccurred extensively within 9 months of treatment interruption, but once again rapidly completely responded to the recommencement of imatinib, with that response being now maintained for over 9 months. This report suggests that dramatic and durable responses to imatinib can be achieved in individual cases despite the lack of specific guidelines in the literature with respect to defining how long treatment with imatinib should be continued in the absence of evidence of tumour progression.
\end{abstract}

\section{Introduction}

Gastrointestinal stromal tumours (GISTs) are uncommon neoplasms representing $<3 \%$ of all gastrointestinal malignancies and accounting for $80 \%$ of gastrointestinal mesenchymal tumours [1]. These rare tumours have an estimated incidence of 1.5 cases per 100,000 persons [2]. GISTs are mostly seen in the gastrointestinal tract, mainly in the fundus of the stomach (60-70\%) or the small intestine (25-35\%), and less commonly in the rectum, oesophagus or colon. However, sporadic primary GISTs arising at sites 
unrelated to the tubular gastrointestinal tract have been reported [3, 4]. Additionally, the management of GISTs has benefitted from the development of anticancer drugs based on specific molecular abnormalities present in cancers. $90 \%$ of GISTs express the c-KIT (CD117) protein, the primary target of the targeted therapeutic agent imatinib mesylate. The introduction of imatinib following surgical resection has markedly improved outcomes in this rare condition.

\section{Case Report}

We report here the case of a 54-year-old male, diagnosed with extensive metastatic GIST, following presentation in June 2002 with left flank pain, anorexia and weight loss of $5 \mathrm{~kg}$ over 4 weeks. An initial abdominal examination revealed a large, tender, intra-abdominal mass arising from his left hypochondrium. Laboratory studies, including blood biochemistry and CEA/CA19.9 tumour markers, were within the normal range and a chest X-ray was also negative.

The subsequent contrast spiral computed tomography (CT) scan of the abdomen and pelvis revealed a lobulated, heterogeneous, low-attenuated mass in the left upper abdomen extending from the left hemi-diaphragm to the lower abdomen anterior to the left kidney (fig. 1 ). The mass measured approximately $180 \times 160 \times 90 \mathrm{~mm}$ and extended to the left lobe of the liver, the lateral wall of the stomach and anterior border of the spleen. A similar lesion was noted in the lower pelvis, posterior to the bladder, measuring $90 \times 80 \times 87 \mathrm{~mm}$. A third lesion in the mid upper pelvic region measured about $35 \mathrm{~mm}$ in diameter. No abnormalities were detected in the liver, pancreas, spleen, adrenal glands or kidney.

The patient proceeded to laparotomy at which time the tumour was debulked. Tumour infiltration was noted to be complex, extending from the epigastrium to the pelvis and involving the spleen, greater curvature of the stomach, mesentery and peritoneal cavity. A post-operative CT scan reported evidence of residual tumour within the omentum, mesentery, pelvis and remaining stomach, measuring $100 \mathrm{~mm}$ in its longest superior-inferior perpendicular diameter and $85 \mathrm{~mm}$ in the longest cross-sectional perpendicular diameter. The patient's post-operative course was complicated by persistent left flank pain and intermittent nausea.

Histopathological examination of the resected tumour confirmed a malignant GIST primarily arising from the stomach wall. Immunohistochemical analysis showed the following immunophenotype: smooth muscle actin (SMA) negative, desmin negative, S100 negative, MNF 116 (broad-spectrum cytokeratin) positive, CD34 positive and c-KIT (CD117) positive.

In view of the presence of extensive residual tumour despite surgical debulking, the patient was commenced on a course of imatinib mesylate. The initial prescribed dose was $400 \mathrm{mg}$ b.i.d. based on evidence from the phase I study by van Oosterom et al. [5]. No evidence of residual disease was noted on CT scan 2 months following the commencement of imatinib. The patient continued to tolerate imatinib well, reporting only an intermittent itch and persistent nausea which was adequately treated with ondansetron $8 \mathrm{mg}$ b.i.d. Three-monthly clinical reviews continued and radiological follow-ups were unremarkable, confirming an excellent complete clinical response to treatment. Due to the lack of evidence in the published literature regarding the ongoing use of imatinib in the treatment of metastatic GIST once a cytogenic response has been achieved, the patient was continued on imatinib indefinitely. In June 2003, the patient's imatinib dosage was changed to $600 \mathrm{mg}$ daily, in line with contemporary treatment guidelines.

Imatinib therapy was ceased some 7 years after its commencement in August 2009, when the patient underwent a left radical nephrectomy to remove an unrelated, localised, $42-\mathrm{mm}$, grade II, renal cell carcinoma involving the upper pole of the left kidney. Imatinib was discontinued at that time due to the patient's slow post-surgical recovery. No evidence of disease recurrence was evident on follow-up CT imaging.

Approximately 9 months after ceasing imatinib therapy, the patient presented with an exacerbation of severe abdominal pain. The pain had been present over the preceding 2 weeks and was associated with significant nausea, vomiting, tiredness and lethargy. A CT scan conducted in May 2010 revealed multiple solid masses within the abdomen and pelvis with the largest mass in the lower abdomen/pelvis, 
measuring $11 \times 11 \mathrm{~cm}$ (fig. 2 , arrows). The lesions were noted to involve the left and right subphrenic spaces, the subcapsular surface of the inferolateral aspect of the liver, the gastro-hepatic ligament region and the left rectus sheath with extension into the underlying peritoneum. Additionally, there was also evidence of gross tumour within the left para-aortic region of the peritoneum and the lower abdomen and pelvis. A CT-guided core biopsy and subsequent histopathological examination of the tumour confirmed recurrent metastatic GIST with immunostains being positive for CD117 and negative for SMA, desmin and S100.

In view of the diagnosis of recurrent disease, the patient was recommenced on imatinib $600 \mathrm{mg}$ daily. Upon review 2 weeks after the recommencement of therapy, the patient's gross abdominal distension had markedly decreased as had his abdominal pain and nausea. A CT scan, performed 6 weeks after the recommencement of imatinib, reported very little evidence of residual malignancy. This patient continues on imatinib $600 \mathrm{mg}$ daily with an excellent sustained clinical response. Serial CT scans confirm a complete response to the reintroduction of imatinib now at 9 months from the time of recurrence. Unfortunately, his ongoing treatment is complicated by persistent nausea.

\section{Discussion}

This case presents the favourable outcome of a patient who originally presented almost 9 years ago with widespread, bulky, metastatic GIST involving the abdomen and pelvis. A sustained complete response was achieved with imatinib and prompted an interruption in treatment 7 years after initial presentation. The disease reoccurred extensively within 9 months of treatment interruption but once again rapidly completely responded to the recommencement of imatinib.

Whereas a decade ago there was no effective systemic therapy available for advanced GIST, the introduction of imatinib, a potent tyrosine kinase inhibitor selectively blocking KIT and PDGFR, into clinical practice has dramatically improved the outcome of patients with advanced GIST. Accordingly, imatinib is now the treatment of choice for c-KITpositive, unresectable and/or metastatic malignant GIST, and for adjuvant treatment for adult patients following resection of c-KIT-positive GIST.

While imatinib has become standard treatment for patients with advanced GIST, it is not known whether imatinib can be stopped in patients in whom disease is controlled. Scientific evidence in this area is scarce and no specific recommendations can as yet be made in regards to the optimal duration of imatinib treatment in the setting of advanced or metastatic GIST. Some studies have reported that imatinib interruption results in rapid progression in most patients with advanced GIST, and cannot be recommended in routine practice unless the patient experiences significant toxicity [6]. This observation was further confirmed in patients who were subsequently randomised in this study after 3 years of imatinib therapy [7]. Findings from a long-term analysis of a randomised phase II trial of standard versus higher dose imatinib for patients with unresectable or metastatic GIST reported that nearly $50 \%$ of patients with advanced disease treated with imatinib survived for more than 5 years irrespective of their starting dose [8].

In terms of clinical outcomes following the discontinuation or interruption of imatinib in the treatment of GIST, some clinical trials show promising results. The most informative data in relation to stopping imatinib for a patient who commenced imatinib for metastatic GIST and subsequently achieved a complete response comes from the BFR14 trial conducted by the French Sarcoma Group. In this study, patients exhibiting either a complete response, partial response or with stable disease were randomised after 1, 3 or 5 years of continuous imatinib to either continue taking imatinib or to stop this 
intervention. The results for patients who were randomised after 1 year of imatinib were published in 2007 and confirmed that progression-free survival of patients with complete response was not significantly different from that of patients with residual tumour in the group who stopped imatinib, with a high risk of relapse even in patients with complete response on CT scan [6].

Blay et al. [6] conducted a prospective, randomised, multicentre, phase III trial comparing interrupted versus continuous treatment of imatinib in 182 patients with advanced GIST beyond 1 year. $31 \%$ of patients treated with continuous imatinib had documented disease progression compared to $81 \%$ in the interrupted imatinib group ( $\mathrm{p}<$ $0.0001)$. The results demonstrated that imatinib treatment interruption resulted in rapid disease progression compared to the patient group receiving continuous treatment. The authors therefore concluded that treatment interruption resulted in rapid progression in most patients with advanced GIST and therefore should not be recommended in standard practice unless the patient experienced significant toxicity.

An update of the BFR-14 trial at a median follow-up of 37 months showed that $91 \%$ of patients in the interrupted arm versus $62 \%$ in the continuous arm experienced progressive disease $(\mathrm{p}<0.0001) .92 \%$ of patients in the interrupted arm achieved tumour control once they recommenced imatinib after first progression. The authors concluded that the reintroduction of imatinib allowed for tumour control in the majority of patients, no unfavourable impact of imatinib interruption on overall survival was noted, and treatment interruption could be a therapeutic option in advanced GIST patients exhibiting intolerance to imatinib [9].

Moreover, Adenis et al. [10] reported that the majority of patient's responding to imatinib treatment relapsed when imatinib was ceased after 3 years of treatment. However, the study findings also concluded that the GIST cells remained sensitive to imatinib during treatment reintroduction. Additionally, imatinib reintroduction at the same dose resulted in tumour control in the majority of patients [11]. Similar results were also observed for those patients who were randomised after 5 years of imatinib. RayCoquard et al. [12] have reported that stopping imatinib after 5 years resulted in a higher rate of disease progression than imatinib maintenance in patients with advanced GIST responding to or stabilised by imatinib.

Lee et al. [13] conducted a prospective study to evaluate the clinical outcome of imatinib interruption in GIST patients who had achieved stable disease or showed better response to imatinib therapy. Following imatinib reintroduction in the interrupted group, $88 \%$ of patients achieved disease control. There were no statistically significant differences in imatinib refractory progression-free survival and overall survival between the groups. The authors concluded that imatinib may be interrupted at least temporarily, in patients with GIST controlled with imatinib when various clinical situations limit continuous treatment.

Several problems may be associated with long-term administration of imatinib [6]. Specifically, patients may experience severe adverse effects requiring treatment interruption. Secondly, patients may not tolerate chronic adverse effects and may request treatment interruption, as occurred in this case. Some series have shown that resistance to imatinib occurs at a median of 24 months and happens in a substantial proportion of patients by 4 years. Such resistance can be related to alteration of pharmacokinetics with 


\begin{tabular}{r|l|l|l}
$\begin{array}{r}\text { Case Reports in } \\
\text { Oncology }\end{array}$ & $\begin{array}{l}\text { Case Rep Oncol 2011;4:204-210 } \\
\text { DOl: 10.1159/000327698 }\end{array}$ & $\begin{array}{l}\text { Published online: } \\
\text { April 6, 2011 }\end{array}$ & $\begin{array}{l}\text { O 2011 S. Karger AG, Basel } \\
\text { ISSN 1662-6575 } \\
\text { www.karger.com/cro }\end{array}$ \\
\hline
\end{tabular}

prolonged exposure, and acquisition of additional mutations in the KIT gene, resulting in imatinib-resistant KIT proteins.

\section{Conclusion}

The limited current evidence would suggest that imatinib needs to be given continuously until disease progression or intolerance in the population of nonprogressive advanced or metastatic GIST patients. The evidence also suggests that the reintroduction of imatinib can re-establish tumour control in most, but not all patients. However, no differences in the incidence of secondary resistance to imatinib or in overall survival have been observed so far. Notwithstanding this, dramatic and sustained responses can be achieved with imatinib in individual cases, as was found in the case reported.

\section{Disclosure Statement}

All authors declare no actual or potential conflicts of interest.

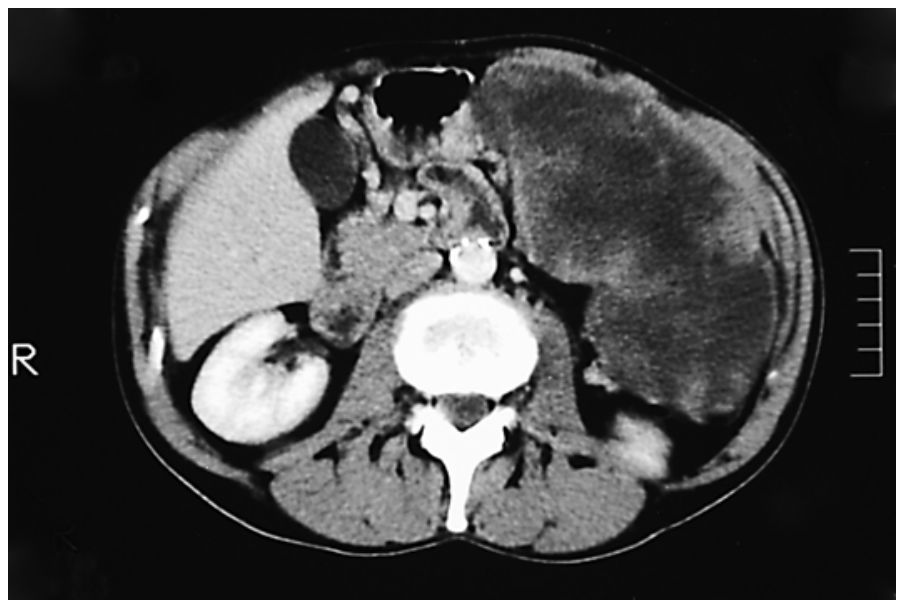

Fig. 1. Abdominal CT finding: CT scan performed in 2002 at the time of the original diagnosis of GIST showing a lobulated, heterogeneous, low-attenuated mass in the left upper abdomen extending from the left hemi-diaphragm to the lower abdomen anterior to the left kidney. 


\begin{tabular}{c|l|l|l}
$\begin{array}{c}\text { Case Reports in } \\
\text { OnCOlOy) }\end{array}$ & $\begin{array}{l}\text { Case Rep Oncol 2011;4:204-210 } \\
\text { DOI: } 10.1159 / 000327698\end{array}$ & $\begin{array}{l}\text { Published online: } \\
\text { April 6, 2011 }\end{array}$ & $\begin{array}{l}\odot \text { 2011 S. Karger AG, Basel } \\
\text { ISSN 1662-6575 } \\
\text { www.karger.com/cro }\end{array}$ \\
\hline
\end{tabular}

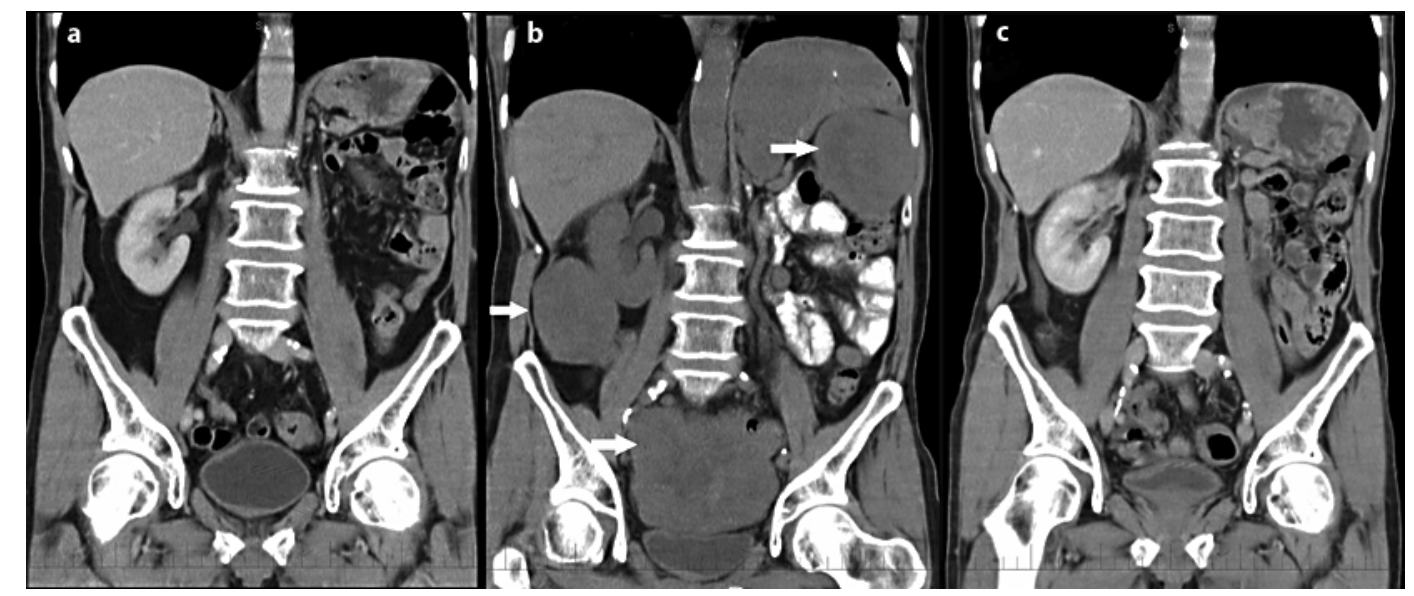

Fig. 2. Serial CT scan images of the patient. a Follow-up CT scan showing no evidence of disease 6 months after cessation of imatinib and 3 months before recurrence was confirmed; $\mathbf{b}$ CT scan performed at the time of disease recurrence showing extensive tumour involving the left subphrenic space; c CT scan 6 months after recommencement of imatinib showing no residual disease.

\section{References}

1 Miettinen M, Lasota J: Gastrointestinal stromal tumors: definition, clinical, histological, immunohistochemical, and molecular genetic features and differential diagnosis. Virchows Arch 2001;438:1-12.

-2 Casali PG, Jost L, Reichardt P, Schlemmer M, Blay JY; ESMO Guidelines Working Group: Gastrointestinal stromal tumours: ESMO clinical recommendations for diagnosis, treatment and follow-up. Ann Oncol 2009;20(suppl 4):64-67.

3 Miettinen M, Majidi M, Lasota J: Pathology and diagnostic criteria of gastrointestinal stromal tumors (GISTs): a review. Eur J Cancer 2002;38(suppl 5):S39-S51.

- Emory TS, Sobin LH, Lukes L, Lee DH, O’Leary TJ: Prognosis of gastrointestinal smooth-muscle (stromal) tumors: dependence on anatomic site. Am J Surg Pathol 1999;23:82-87.

-5 van Oosterom AT, Judson I, Verweij J, Stroobants S, Donato di Paola E, Dimitrijevic S, Martens M, Webb A, Sciot R, Van Glabbeke M, Silberman S, Nielsen OS; European Organisation for Research and Treatment of Cancer Soft Tissue and Bone Sarcoma Group: Safety and efficacy of imatinib (STI571) in metastatic gastrointestinal stromal tumours: a phase I study. Lancet 2001;358:1421-1423.

-6 Blay JY, Le Cesne A, Ray-Coquard I, Bui B, Duffaud F, Delbaldo C, Adenis A, Viens P, Rios M, Bompas E, Cupissol D, Guillemet C, Kerbrat P, Fayette J, Chabaud S, Berthaud P, Perol D: Prospective multicentric randomized phase III study of imatinib in patients with advanced gastrointestinal stromal tumors comparing interruption versus continuation of treatment beyond 1 year: the French Sarcoma Group. J Clin Oncol 2007;25:1107-1113.

7 Le Cesne A, Ray-Coquard I, Bui BN, Adenis A, Rios M, Duffaud F, Bertucci F, Chabaud S, Emile J, Blay J: Time to onset of progression after imatinib interruption and outcome of patients with advanced GIST: results of the BFR-14 prospective French Sarcoma Group randomized phase III trial. J Clin Oncol 2010;28:Abstract 10033.

-8 Blanke CD, Demetri GD,von Mehren M, Heinrich MC, Eisenberg B, Fletcher JA, Corless CL, Fletcher CD, Roberts PJ, Heinz D, Wehre E, Nikolova Z, Joensuu H: Long term results from a randomised phase II trial of standard versus higher dose imatinib mesylate for patients with unresectable or metastatic gastrointestinal stromal tumours expressing KIT. J Clin Oncol 2008;26:620-625.

9 Rios M, Le Cesne A, Bui B, Adenis A, Bertucci F, Duffaud F, Emile J, Chabaud S, Perol D, Blay J; French Sarcoma Group: Interruption of imatinib (IM) in GIST patients with advanced disease after one year of treatment: updated results of the prospective French Sarcoma Group randomized phase III trial on long term survival. J Clin Oncol 2007;25:Abstract 10016.

10 Adenis A, Penel N, Blay JY: Imatinib in gastrointestinal stromal tumor: does treatment duration matter? Oncology 2009;77:157-161. 
11 Perol D, Domont J, Ray-Coquard IL, Bui BN, Rios M, Duffaud F, Bertucci F, Moneron C, Chabaud S, Le Cesne A, Blay JY: Does interruption of imatinib (IM) in responding GIST patients after one year of treatment influence the secondary resistance of IM after its reintroduction? Updated results of the French Sarcoma Group randomized phase III trial on long term survival. J Clin Oncol 2008;26:567s, Abstract 10556.

12 Ray-Coquard IL, Bui BN, Adenis A, Rios M, Bertucci F, Chabaud S, Perol D, Blay J, Le Cesne A, Fremch Sarcoma Group: Risk of relapse with imatinib (IM) discontinuation at 5 years in advanced GIST patients: Results of the prospective BFR-14 randomized phase III study comparing interruption versus continuation of IM at 5 years of treatment: A French Sarcoma Group Study. J Clin Oncol 2010;28:Abstract 10033.

13 Lee JL, Ryu MH, Chang HM, Kim TW, Kang HJ, Sohn HJ, Lee JS, Kang YK: Clinical outcome in gastrointestinal stromal tumor patients who interrupted imatinib after achieving stable disease or better response. Jpn J Clin Oncol 2006;36:704-711. 